\title{
Ginsenoside Rg3 inhibits the senescence of prostate stromal cells through down-regulation of interleukin 8 expression
}

\author{
Yanfei Peng ${ }^{1, *}$, Ran Zhang ${ }^{2,}{ }^{*}$, Lingfei Kong ${ }^{2}$, Yongmei Shen ${ }^{2}$, Da $\mathrm{Xu}^{3}$, Fang Zheng ${ }^{1}$, \\ Jianwei Liu ${ }^{1}$, Qian $\mathrm{Wu}^{1}$, Bona Jia ${ }^{2}$ and Ju Zhang ${ }^{2}$ \\ ${ }^{1}$ School of Integrative Medicine, Tianjin University of Traditional Chinese Medicine, Tianjin, China \\ 2 Department of Biochemistry and Molecular Biology, College of Life Science, Bioactive Materials Key Lab of Ministry of \\ Education, Nankai University, Tianjin, China \\ ${ }^{3}$ Department of Pharmaceutics, School of Pharmacy, Rutgers University, New Brunswick, New Jersey, USA \\ * These authors contributed equally to this study and share first authorship \\ Correspondence to: Yanfei Peng, email: pengyanfei@tjutcm.edu.cn
}

Ju Zhang, email: zhangju@nankai.edu.cn

Keywords: ginsenoside Rg3; IL-8; prostate cancer; senescence; stromal cell; Gerotarget

Received: July 07, $2016 \quad$ Accepted: April 18, $2017 \quad$ Published: May 04, 2017

Copyright: Peng et al. This is an open-access article distributed under the terms of the Creative Commons Attribution License 3.0 (CC BY 3.0), which permits unrestricted use, distribution, and reproduction in any medium, provided the original author and source are credited.

\section{ABSTRACT}

Senescent stromal cells support the development of prostate cancer and are considered potential therapeutic targets. This research evaluated the regulatory effects of ginsenoside Rg3 on the senescence of prostatic stromal cells pre-incubated in medium supplemented with $0.5 \%$ fetal bovine serum. The results revealed that ginsenoside Rg3 decreased the number of stromal cells positively stained with a senescent cell marker (senescence-associated $\beta$-galactosidase). Ginsenoside Rg 3 also increased the viability of stromal cells and promoted cell cycle transition from G0/G1 to $S$ phase, as well as inhibited the carcinoma-associated fibroblast-like phenotype in prostate stromal cells, through the up-regulation of smooth muscle cell markers SM22 and smooth muscle myosin heavy chain. Conditioned medium collected from stromal cells treated with ginsenoside Rg3 exhibited an attenuated effect on the promotion of prostate cancer cell migration compared with conditioned medium from stromal cells without Rg3 treatment. Down-regulation of interleukin 8 (IL-8) in a dose- and time-dependent manner was observed in ginsenoside Rg3-treated stromal cells, and over-expression or addition of IL-8 reversed the anti-senescence role of Rg 3 in prostate stromal cells. Furthermore, ginsenoside Rg 3 down-regulated IL-8 expression by decreasing the reactive oxygen species level in prostatic stromal cells and reducing the transcriptional activity of IL-8 promoter by damping the transcription factors C/EBP $\beta$ and p65 binding to IL-8 promoter. Our research revealed that ginsenoside Rg3 was able to inhibit prostate stromal cell senescence by down-regulating IL-8 expression. The results suggest a potential value for ginsenoside $\mathbf{R g} 3$ in prostate cancer treatment through the targeting of pro-carcinogenic senescent stromal cells.

\section{INTRODUCTION}

Senescence is a specific cellular status under a variety of stimuli with stable cell cycle arrest. Cellular senescence can be classified into replicative and premature. Replicative senescence, induced by telomere shortening during DNA replication, exists in most mammal somatic cells and is presumed to contribute to organismal aging in later adult life, while premature cellular senescence is usually induced by DNA damage, activation of oncogenic signaling, nutrition deprivation or reactive oxygen species (ROS) accumulation. Recent research compared gene expression profiles between replicative senescent cells and cells arrested by DNA damage or serum starvation and 
revealed that only a small subset of genes were exclusively regulated in replicative senescent cells while the majority of expression changes in the three conditions were similar [1].

Cellular senescence may prevent the malignant transformation of cells through the avoidance of excessive proliferation-accumulated DNA mutations. However, in some heterogeneous tissues such as prostate, senescent stromal cells effectively support the progression of epithelium-derived cancer and are postulated as novel therapeutic targets in cancer treatment [2]. Isolated stromal fibroblasts from elderly men (63 to 81 years old), but not from young men (40 to 52 years old), have been reported to promote the proliferation of prostate epithelial cells by highly expressing CXCL12 [3]. Other research has reported the up-regulation of growth factors and chemokines in senescent prostate stromal cells, inducing the proliferation of cancer cells in a paracrine manner [4]. Recent research indicated that senescent stromal cells supported cancer cell proliferation by secreting energyrich compounds, induced epithelial-to-mesenchymal transition progression, and subsequently promoted cancer aggressiveness, as well as contributed to the immune escape of cancer cells [5]. Moreover, senescent stromal cells also enhanced the chemoresistance of cancer cells in a paracrine manner [6]. These reports suggest senescent stroma is a potential therapeutic target in prostate cancer treatment.

Ginsenoside $\mathrm{Rg} 3$, extracted from a traditional medical herb, ginseng, has been reported as a relatively safe drug with anticancer activity both in vitro and in vivo $[7,8]$. Previous studies evaluating the effects of ginsenoside $\mathrm{Rg} 3$ on prostate cancer cells have revealed that the compound inhibited the proliferation and migration of cancer cells, as well as enhanced the susceptibility of cancer cells to chemotherapeutic drugs by inhibiting the NF- $\kappa$ B signaling pathway [9-11]. The beneficial effects of ginsenoside $\mathrm{Rg} 3$ on prostate cancer cells have been well recognized, while the impact of this compound on stromal cells is still ambiguous.

In this study, we report the anti-senescence role of ginsenoside $\operatorname{Rg} 3$ in prostate stromal cells pre-incubated in medium with low serum concentration. Our results suggest that ginsenoside $\mathrm{Rg} 3$ also regulates the phenotype of stromal cells and blocks the promoting effects of stromal cells on prostate cancer cell migration. Furthermore, decrease of IL-8 expression was observed in ginsenoside Rg3-treated stromal cells and down-regulation of IL-8 was essential for the anti-senescence role of ginsenoside $\mathrm{Rg} 3$. The research also uncovered that ginsenoside Rg3 attenuated IL-8 expression by damping ROS level and transcriptional activity of IL- 8 gene promoter. In conclusion, our results suggested potential beneficial effects of ginsenoside Rg3 in prostate cancer treatment, by the targeting of the stromal component, especially in the senescent stromal environment.

\section{RESULTS}

\section{Ginsenoside Rg3 prevented the senescence of prostate stromal cells in vitro}

Senescence-associated $\beta$-galactosidase (SA- $\beta$-gal) is commonly used as a marker of cellular senescence. In this study, normal prostatic stromal cells WPMY-1, NAF, and carcinoma-associated fibroblasts (CAF) cells were cultured in DMEM medium supplemented with $0.5 \%$ fetal bovine serum (FBS) for $36 \mathrm{~h}$ and subsequently treated with vehicle (DMSO) or $25 \mu \mathrm{M}$ ginsenoside Rg3 for another 48 h. In all 3 cell lines, cell percentages of SA- $\beta$-gal positive staining were significantly down-regulated by ginsenoside Rg3 treatment (Figure 1A and 1B). Cell cycle arrest was also evaluated by flow cytometry analysis and the results showed that ginsenoside Rg3 promoted the transition of the cell cycle from G0/G1 to S phase in WPMY-1 normal stromal cells and CAF carcinoma-associated stromal cells (Figure 1C). Not only was the viability of WPMY-1 and NAF cells enhanced by ginsenoside Rg3, but also the proliferation of WPMY-1 (Figure 1D and 1E). We also studied the effects of ginsenoside Rg3 on primary cultured rat prostate stromal cells and found that the compound not only inhibited the senescence of serum-starved cells but also delayed replicative senescence (Supplementary Figure 1). All these results indicated that ginsenoside Rg3 is an anti-senescent compound in prostate stromal cells.

\section{Ginsenoside Rg3 up-regulated the expression of the smooth muscle cell markers SM22 and smooth muscle myosin heavy chain (SMMHC) in WPMY- 1 and NAF cells}

The heterogeneity of prostate stromal cells has been widely characterized [12]. The cells mainly comprise fibroblasts and smooth muscle cells with diverse phenotypes. The phenotypic variation of prostate stromal cells has been observed in benign prostatic hyperplasia $(\mathrm{BPH})$ and prostate cancer. In this research, immunofluorescence assays were performed to analyze phenotypic markers in WPMY-1 and NAF (Figure 2A), revealing that ginsenoside $\mathrm{Rg} 3$ up-regulated the expression of smooth muscle cell markers SM22 and SMMHC. The same results were obtained by western blot assay (Figure 2B).

\section{Ginsenoside Rg3 blocked the promoting effects of WPMY-1 on cancer cell migration}

Senescent prostate stromal cells promoted cancer cell migration in a paracrine manner. Unconditioned medium (DMEM-CTRL and DMEM-Rg3) and 


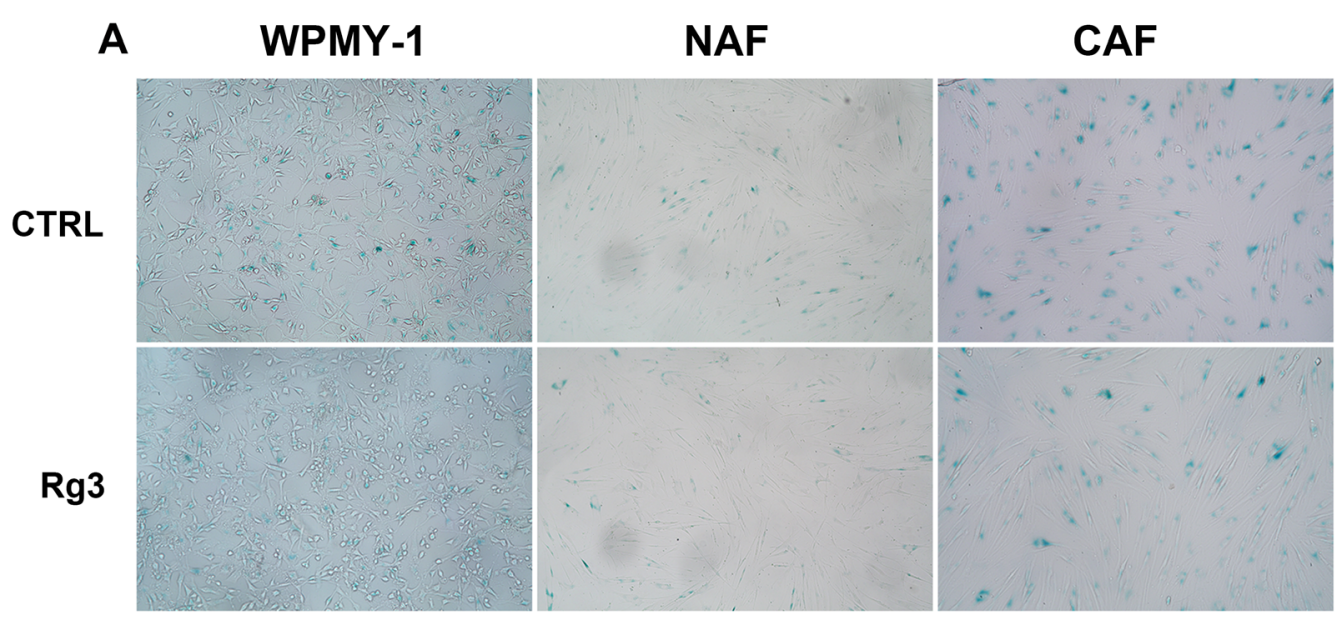

B
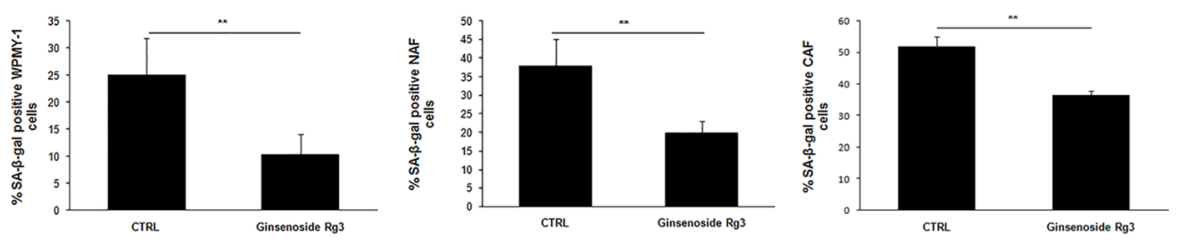

C

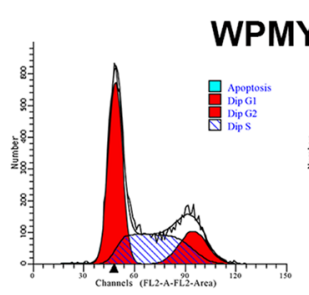

CTRL

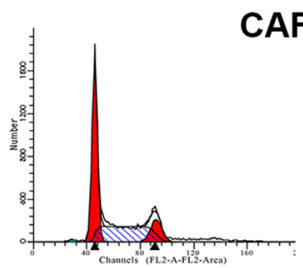

CTRL

D

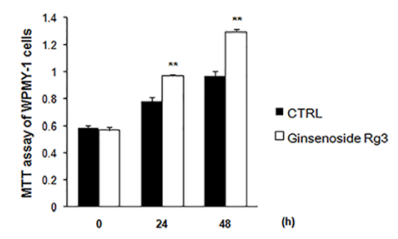

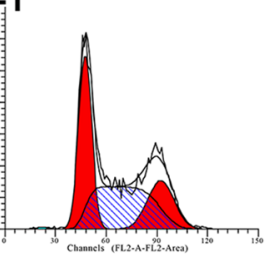

Rg3
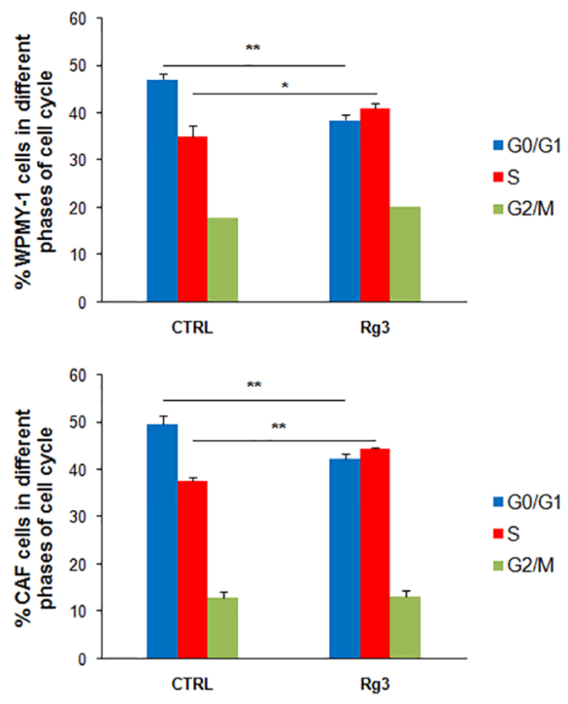

E
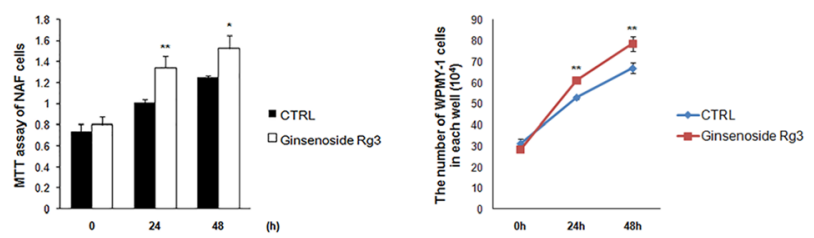

Figure 1: Ginsenoside Rg3 inhibited senescence of prostate stromal cells incubated in serum starvation condition. A. Images showing SA- $\beta$-gal staining in WPMY-1, NAF, and CAF cells. B. Quantitative analysis of the percentage of SA- $\beta$-gal positive stained cells. C. Flow cytometry assay results indicating that Rg3 promoted the cell cycle from G0/G1 to S phase in WPMY-1 and CAF cells. D. MTT assay results revealing that ginsenoside Rg3 enhanced the viability of WPMY-1 and NAF cells. E. Graph demonstrating that ginsenoside Rg3 increased the proliferation of WPMY-1 cells. Images of WPMY-1 and NAF were collected at $\times 100$ magnification. Images of CAF were at $\times 200$ magnification. The results were obtained from 3 independent experiments and are presented as means $\pm \mathrm{SD}$. $* p<0.05 ; * * p<0.01$. 
conditioned medium (CM) collected from stromal cells treated with vehicle (CM-CTRL) or ginsenoside Rg3 (CM-Rg3) were used to treat PC3 prostate cancer cells for $24 \mathrm{~h}$ in wound-healing assays. CM-CTRL from WPMY1 significantly promoted the migration of PC3 compared with DMEM-CTRL, while the pro-migratory activity of stromal cells could be reversed by ginsenoside $\mathrm{Rg} 3$ (Figure 3A and 3B). Transwell assays were also performed to verify the results (Figure 3C and 3D). Moreover, other wound-healing assays demonstrated that ginsenoside $\mathrm{Rg} 3$ also blocked the promoting effects of NAF on cancer cell migration (Supplementary Figure 2).

\section{Ginsenoside Rg3 inhibited IL-8 expression in prostatic stromal cells}

IL-8 has been reported as up-regulated in senescent fibroblast cells where it contributes to the establishment of a special senescence-associated secretion phenotype
(SASP) [13]. In this research, the expression of several factors was detected in stromal cells treated with or without ginsenoside Rg3. IL-8 mRNA expression in WPMY-1 cells and the protein concentration in corresponding CM were significantly down-regulated in a time-dependent manner following treatment with $\mathrm{Rg} 3$ (Figure 4A and 4B). Different doses of ginsenoside Rg3 $(0,6.25 \mu \mathrm{M}, 12.5 \mu \mathrm{M}$, and $25 \mu \mathrm{M})$ were used to treat WPMY-1 cells and dose-dependent down-regulation of IL-8 expression was observed (Figure 4C and 4D). Rg3 also decreased IL-8 expression in NAF cells, both at mRNA and protein level (Figure 4E and 4F).

Over-expression or exogenous addition of IL-8 blocked the preventive effects of ginsenoside Rg3 on prostate stromal cell senescence

Previous reports about the role of IL- 8 in cellular senescence have been inconsistent. Acosta and Gil [14]

A

SM22

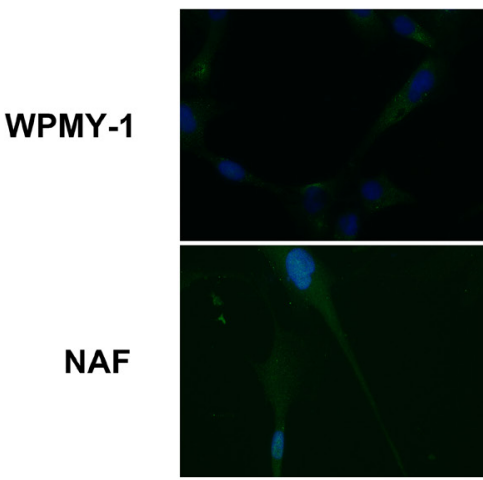

CTRL

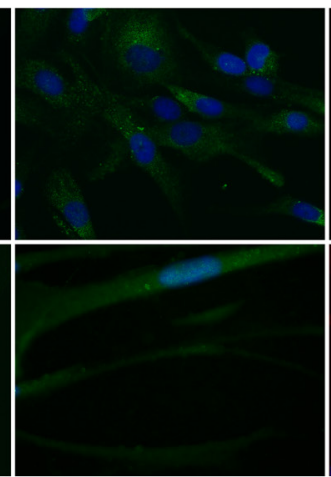

Rg3

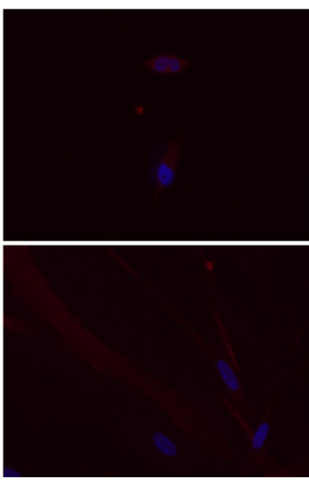

CTRL
SMMHC

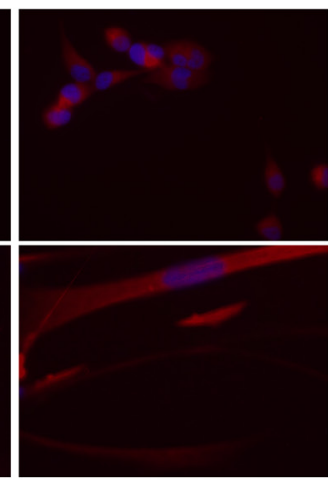

Rg3

\section{B}
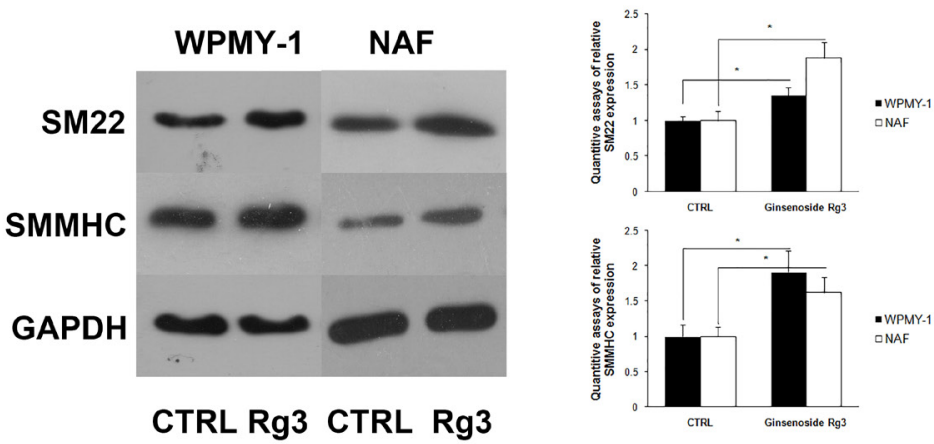

Figure 2: Ginsenoside Rg3 increased SM22 and SMMHC expression in WPMY-1 and NAF cells. A. Immunofluorescence assays indicating the up-regulation of SM22 (green) and SMMHC (red) induced by ginsenoside Rg3 in WPMY-1 and NAF cells. Blue fluorescence indicates the nucleus stained by DAPI. The images were collected at $\times 400$ magnification. B. Western blot assays verifying the results from immunofluorescence. The results were also quantified with Image $\mathrm{J}$ software and are presented as means $\pm \mathrm{SD}$. ${ }^{*} p<0.05$. 
discovered that depletion of IL-8 receptor CXCR2 delayed both replicative and oncogenic signal-induced senescence. However, other research has reported that IL-8 may prevent oxidative-stress-induced human endothelial cell senescence [15]. In our study, the plasmid PCDNA3.1IL8 was constructed and transfected into WPMY-1 cells, and IL- 8 over-expression was confirmed by measurement of the protein concentration in CM (Figure 5A). Overexpression of IL-8 reversed ginsenoside Rg3-decreased SA- $\beta$-gal positive staining in WPMY-1 cells, while transfection with empty plasmid PCDNA3.1 (+) had no impact on the effects of ginsenoside Rg3. Similarly, exogenous addition of IL-8 to WPMY-1 cells also blocked the anti-senescent role of ginsenoside Rg3 (Figure 5B, $5 \mathrm{C}$, and 5D). Also, the addition of IL- 8 antagonized Rg3-inhibited NAF senescence (Supplementary Figure 3). Furthermore, IL-8 addition reversed the damping role of ginsenoside Rg3 in WPMY-1 cell-induced cancer cell migration (Supplementary Figure 4). These results suggested that IL-8 down-regulation was pivotal for ginsenoside $\mathrm{Rg} 3$-induced anti-senescence in prostate stromal cells.

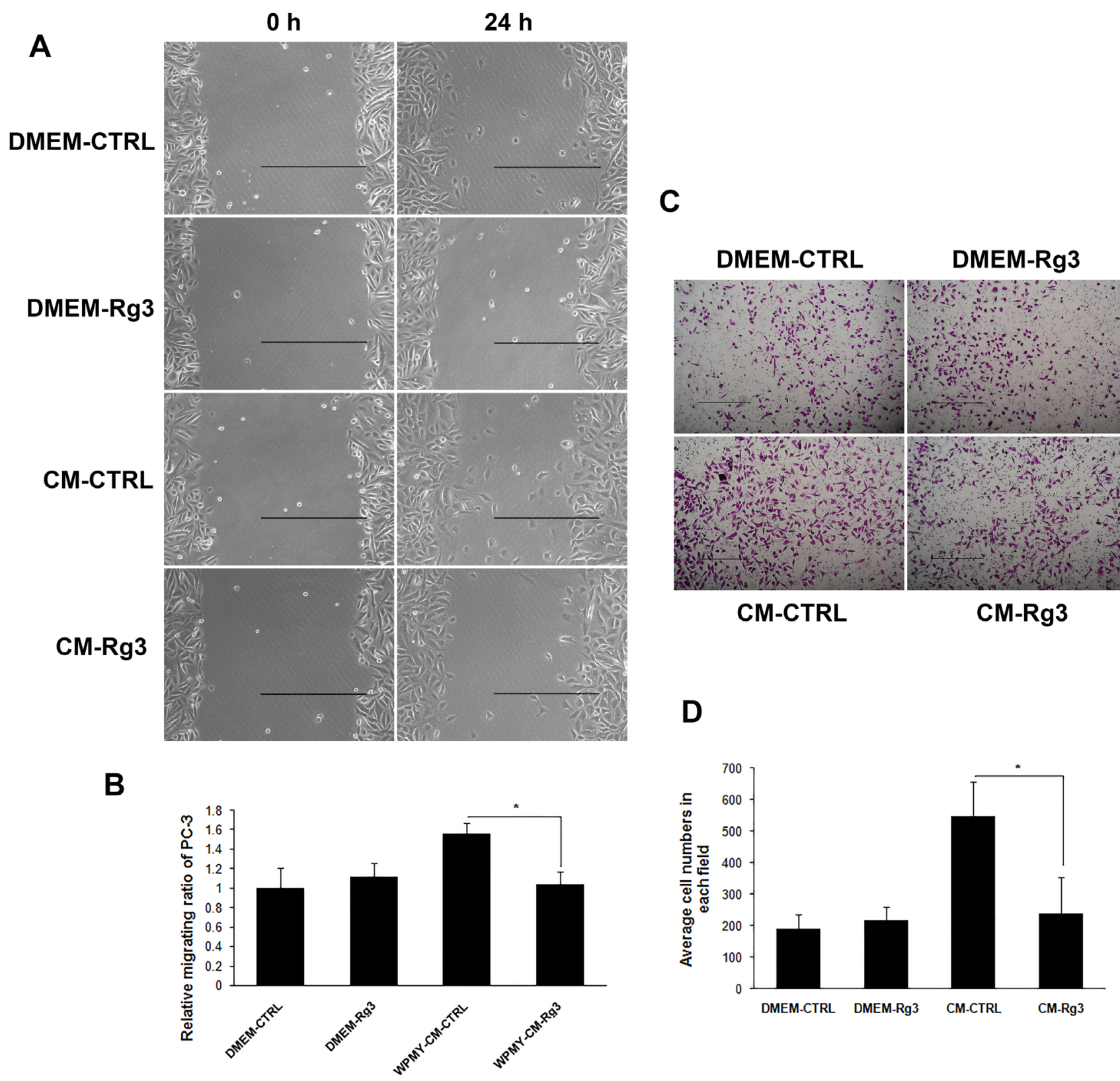

Figure 3: Ginsenoside Rg3 inhibited PC3 cell migration through the modulation of WPMY-1 cell paracrine. A. Wound healing assays of PC 3 cells at 0 and $24 \mathrm{~h}$. The images were collected at $\times 200$ magnification. Scale bar, $500 \mu \mathrm{m}$. B. Quantification of the results from wound healing assays. C. Transwell assays of PC3 cells at 0 and $24 \mathrm{~h}$. The pictures were captured at $\times 100$ magnification. Scale bar, $500 \mu \mathrm{m}$. D. Quantification of the results from transwell assays. The results were obtained from 3 independent experiments and are presented as means $\pm \mathrm{SD} . * p<0.05$. 


\section{Ginsenoside Rg3 inhibited IL-8 expression by decreasing the cellular ROS level}

The exact molecular mechanism of Rg3 downregulation of IL-8 expression was further explored. ROS, an indicator of cellular oxidative stress, has been reported to regulate IL-8 expression [16], and ginsenoside Rg3 has been found to suppress LPS- or UV-irradiationinduced ROS levels in macrophage and in the keratinocyte cell line $\mathrm{HaCaT}$ [17]. In our study, ROS levels were significantly attenuated in WPMY-1 cells treated with ginsenoside $\mathrm{Rg} 3$ for $24 \mathrm{~h}$, while the addition of $\mathrm{H}_{2} \mathrm{O}_{2}$
A

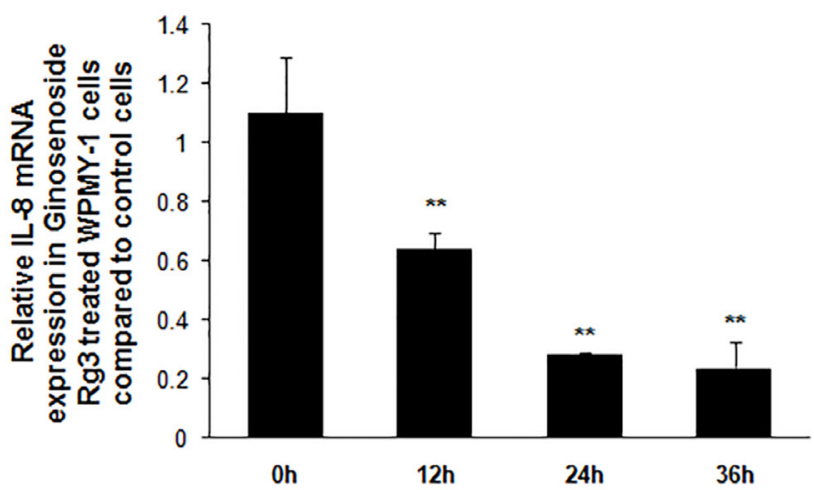

C

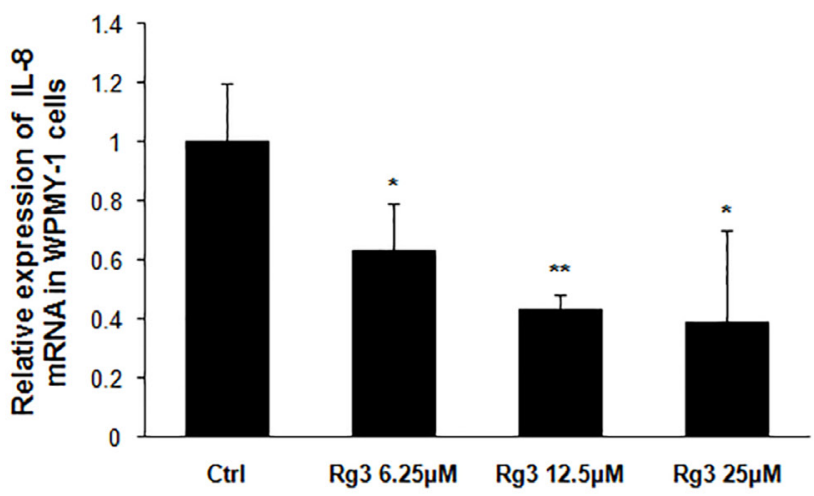

E

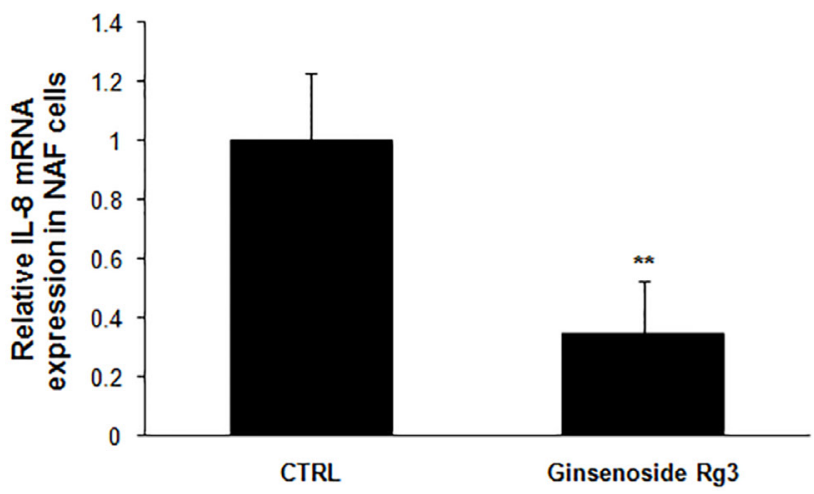

B
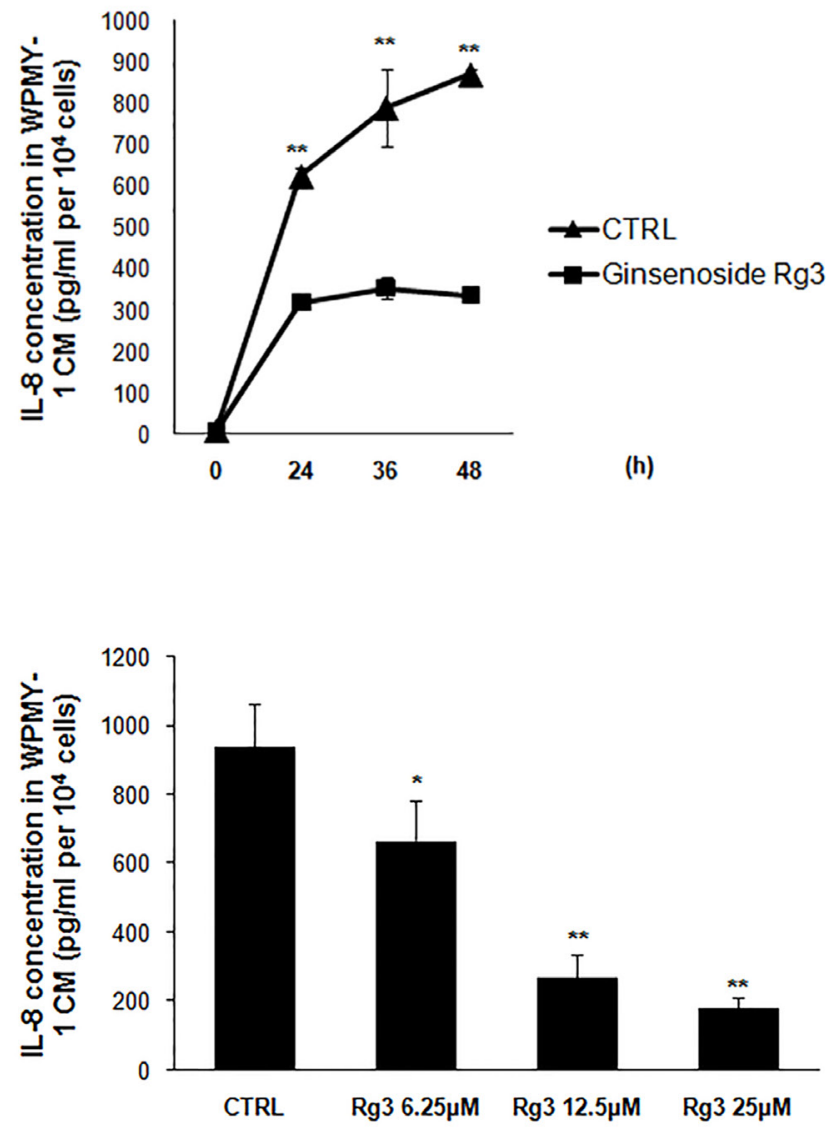

$\mathbf{F}$

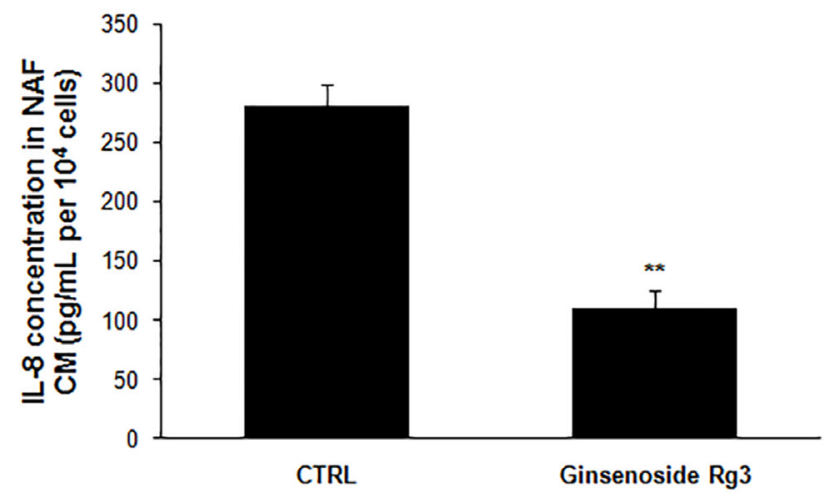

Figure 4: Ginsenoside Rg3 inhibited IL-8 expression in prostate stromal cells. A. and B. show that ginsenoside Rg3 decreased IL-8 expression in a time-dependent manner in WPMY-1 cells. C. and D. show that ginsenoside Rg3 decreased IL-8 expression in a dosedependent manner in WPMY-1 cells. E. and F. show that ginsenoside Rg3 inhibited IL-8 expression in NAF cells. The results were obtained from 3 independent experiments and are presented as means \pm SD. ${ }^{*} p<0.05 ; * * p<0.01$. 
blocked the regulatory effect of ginsenoside $\mathrm{Rg} 3$ on ROS level (Figure 6A). Additionally, IL-8 down-regulation induced by ginsenoside Rg3 was completely antagonized by the addition of $\mathrm{H}_{2} \mathrm{O}_{2}$ (Figure $6 \mathrm{~B}$ and $6 \mathrm{C}$ ). $\mathrm{CoCl}_{2}$, which was used to induce cell hypoxia, increased ROS in WPMY-1 cells, as well as blocked the regulatory effects of ginsenoside $\mathrm{Rg} 3$ on ROS level and IL-8 expression. However, the scavenger of ROS, N-acetyl-L-cysteine (NAC) was able to significantly down-regulate ROS levels and IL-8 protein expression in $\mathrm{CoCl}_{2}$-treated WPMY-1 cells (Supplementary Figure 5).

\section{Ginsenoside Rg3 attenuated the transcriptional activity of IL-8 gene promoter}

Three luciferase reporter plasmids, including IL-8 promoter fragments with different lengths - IL-8 pro L $(-1481 \mathrm{nt}$ to $+44 \mathrm{nt})$, IL-8 pro M $(-765 \mathrm{nt}$ to $+44 \mathrm{nt})$, and IL-8 pro $\mathrm{S}(-176 \mathrm{nt}$ to $+44 \mathrm{nt})$ - were transfected into WPMY1 cells and then treated with DMSO or ginsenoside Rg3 for $36 \mathrm{~h}$. The transcriptional activity of all 3 IL-8 promoter fragments was down-regulated by ginsenoside

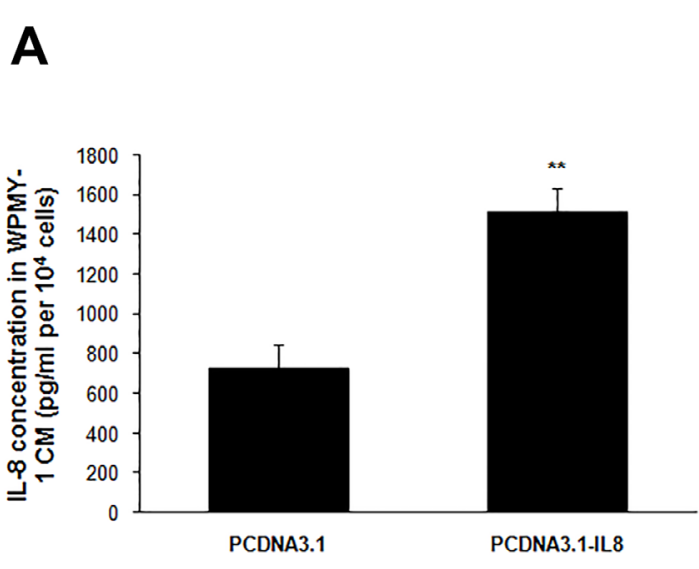

C

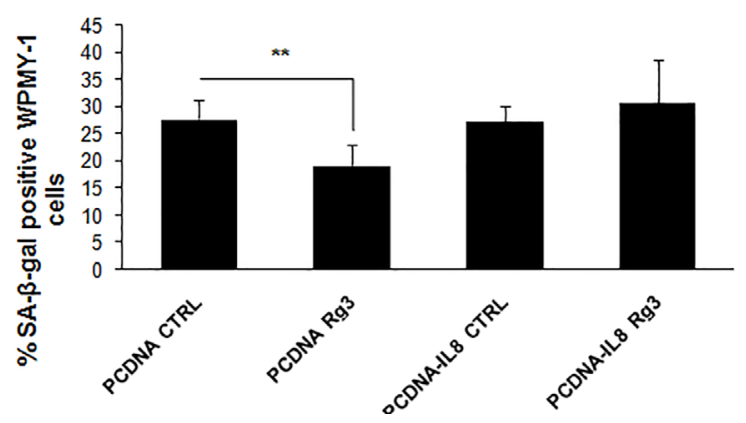

PCDNA3.1

B

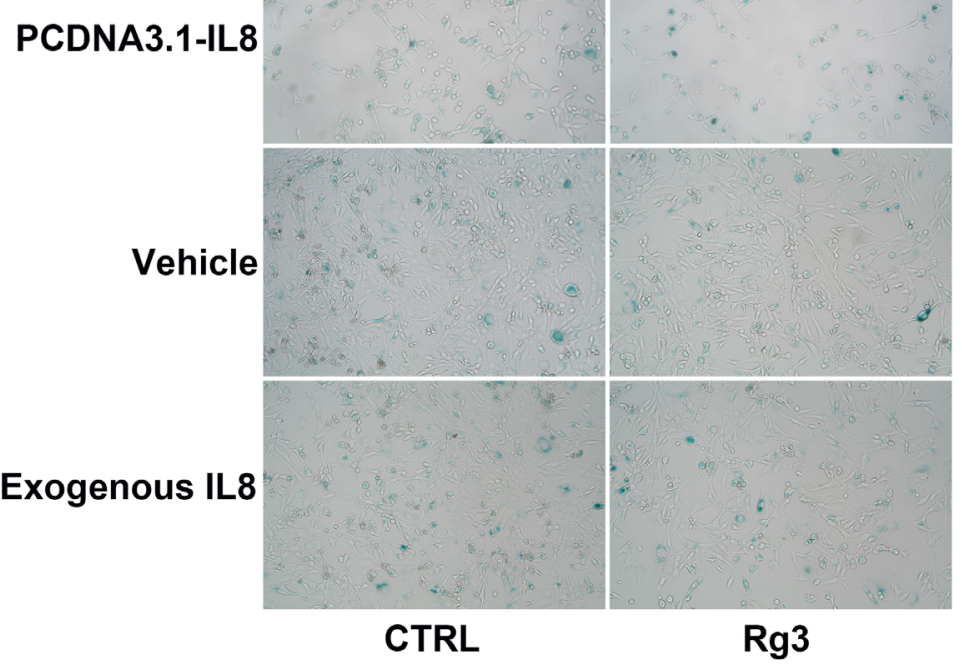

D

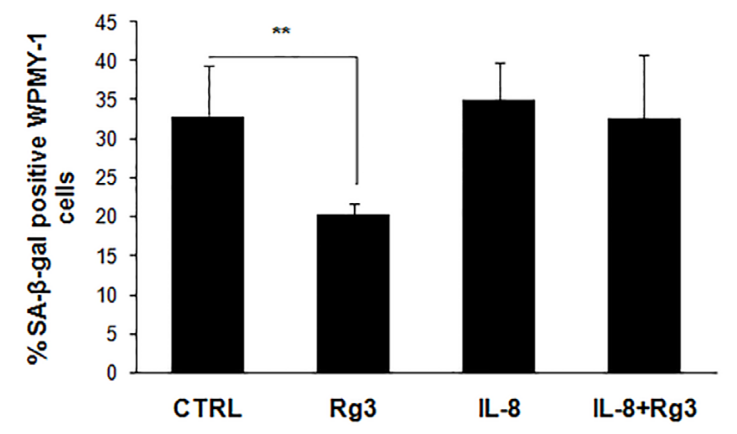

Figure 5: Over-expression or exogenous addition IL-8 blocked ginsenoside Rg3-inhibited prostate stromal cell senescence. A. Results of ELISA assays confirming the over-expression of IL-8 in WPMY-1 cells transfected with PCDNA3.1-IL8. B. shows SA- $\beta$-gal staining in WPMY-1 cells transfected with empty vector or PCDNA3.1-IL8 and treated with vehicle or ginsenoside Rg3 as well as SA- $\beta$-gal staining in WPMY-1 cells treated with vehicle, $\operatorname{Rg} 3$, exogenous IL-8, and Rg3+exogenous IL-8. C. and D. show the quantitative analysis of the percentage of positive staining cells in (B). The results were obtained from 3 independent experiments and are presented as means $\pm \mathrm{SD}$. $* * p<0.01$. 
A CTRL
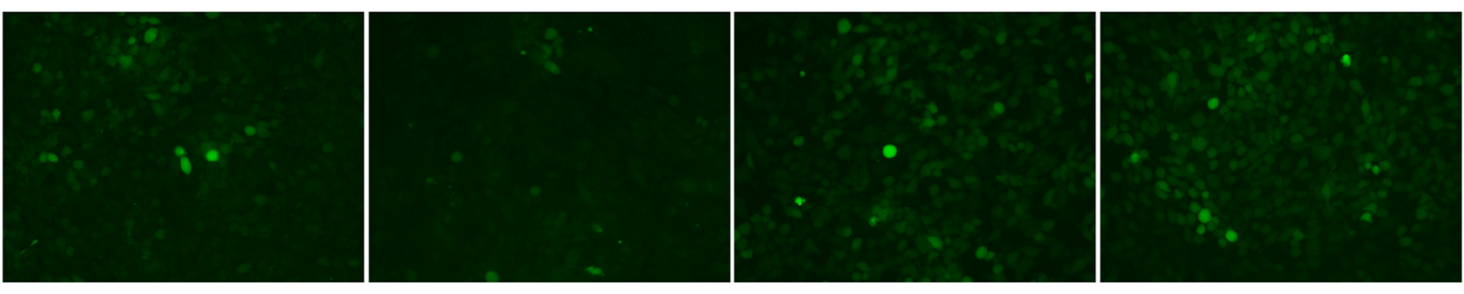

B

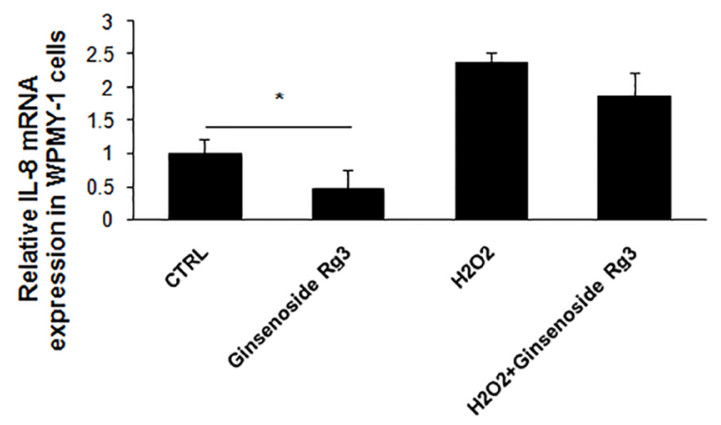

D

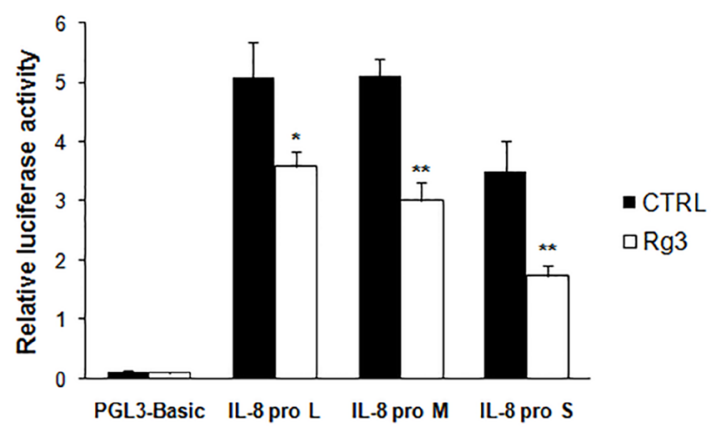

$\mathbf{F}$

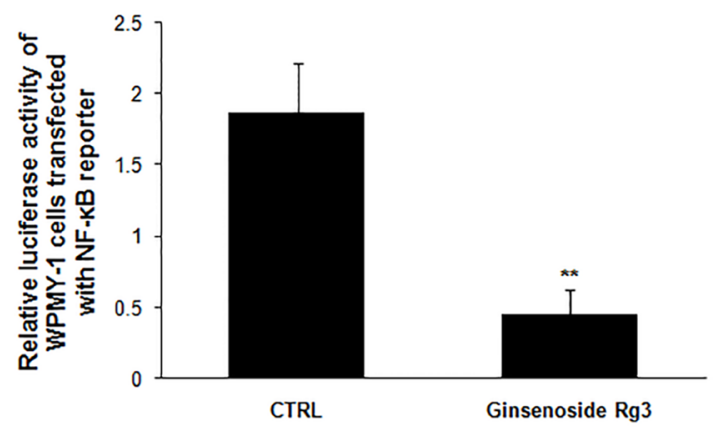

C

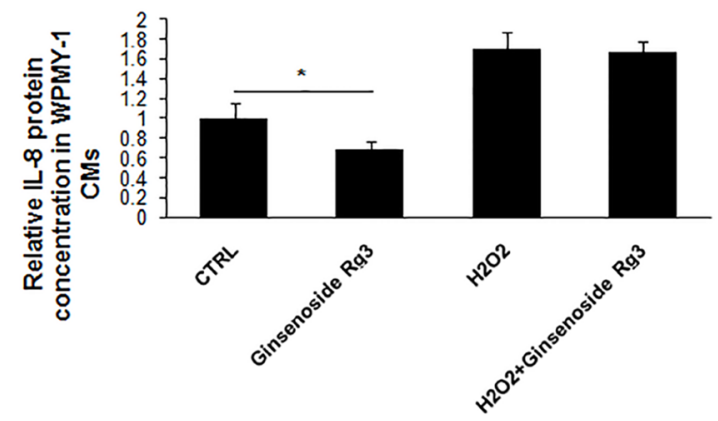

E

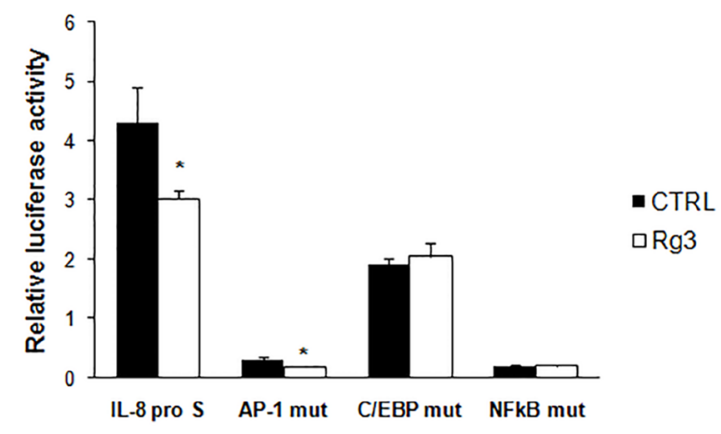

G
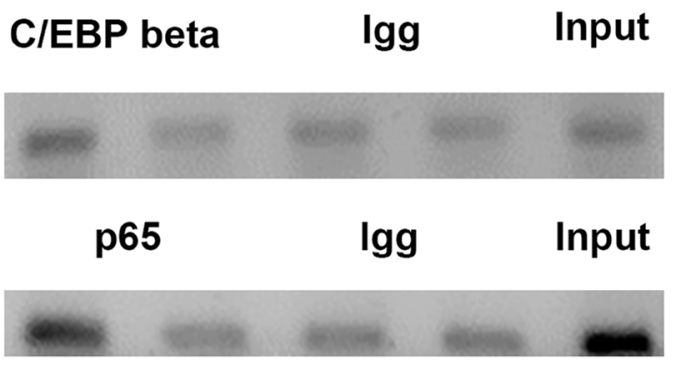

CTRL Rg3 CTRL Rg3

Figure 6: Ginsenoside Rg3 inhibited IL-8 expression in WPMY-1 cells through down-regulation of cellular ROS levels and the transcriptional activity of IL-8 gene promoter. A. shows images from the use of DCFH-DA to analyze cellular ROS levels in WPMY-1 treated with vehicle, $\mathrm{Rg} 3, \mathrm{H}_{2} \mathrm{O}_{2}$, and $\mathrm{H}_{2} \mathrm{O}_{2}+\mathrm{Rg} 3$. The images were collected at $\times 200$ magnification. B. and C. show that $\mathrm{H}_{2} \mathrm{O}_{2}$ treatment antagonized the inhibitory role of $\mathrm{Rg} 3$ on IL-8 expression. D. shows luciferase reporter assay results indicating that ginsenoside Rg3 down-regulated the transcriptional activity of IL-8 promoter. E. demonstrates mutation of C/EBP $\beta$ or NF-kB binding site on IL-8 promoter blocked the inhibitory role of ginsenoside Rg3 on IL-8 promoter transcriptional activity. F. Luciferase reporter assay results indicating that ginsenoside Rg3 inhibited NF-kB pathway in WPMY-1 cells. G. ChIP assays indicating ginsenoside Rg3 attenuated transcription factor C/EBP $\beta$ and p65 binding to IL-8 promoter. The results were obtained from 3 independent experiments and are presented as means $\pm \mathrm{SD}$. ${ }^{*} p<0.05 ; * * p<0.01$. 
Rg3, suggesting that the regulatory sites responding to ginsenoside $\mathrm{Rg} 3$ treatment are located in the shortest fragment (-176nt to $+44 \mathrm{nt}$ ) (Figure 6D). Three main transcription factors AP-1, C/EBP $\beta$, and NF- $\kappa$ B are able to bind to this fragment [18]. Each binding site on IL-8 pro $\mathrm{S}$ was mutated and the regulatory effects of ginsenoside $\mathrm{Rg} 3$ on transcriptional activity were completely blocked when $\mathrm{C} / \mathrm{EBP} \beta$ or NF- $\kappa \mathrm{B}$ binding site was mutated. Both AP-1 and $\mathrm{NF}-\kappa \mathrm{B}$ binding site mutation significantly decreased the basic transcriptional activity of IL- 8 promoter (Figure $6 \mathrm{E}$ ). A luciferase reporter plasmid (containing $4 \mathrm{NF}-\kappa \mathrm{B}$ conserved motifs) was transfected into WPMY-1 cells, and ginsenoside $\mathrm{Rg} 3$ down-regulated both the basic and $\mathrm{TNF} \alpha$-enhanced luciferase activity significantly (Figure $6 \mathrm{~F}$ and Supplementary Figure 6). These results demonstrated that Rg3 inhibited NF- $\mathrm{KB}$ signaling pathway activation in WPMY-1 cells. Moreover, chromatin immunoprecipitation (ChIP) assays demonstrated that ginsenoside $\mathrm{Rg} 3$ attenuated $\mathrm{C} / \mathrm{EBP} \beta$ and $\mathrm{p} 65$ binding to the corresponding sites (Figure 6G). Another ChIP assay indicated that $\mathrm{H}_{2} \mathrm{O}_{2}$ addition blocked the regulatory effects of ginsenoside $\mathrm{Rg} 3$ on p65 binding to IL-8 promoter (Supplementary Figure $6 \mathrm{~B})$.

\section{DISCUSSION}

The accumulation of senescent cells has been demonstrated during organism aging [19], which suggests that senescent cells may play a role in aging-associated disease, including prostate cancer. Cellular senescence seems to exhibit diverse effects on epithelial and stromal cells in prostate cancer $[20,21]$. Senescence is considered to prevent normal prostate epithelial cells from neoplasia as epithelial senescence exists in BPH and prostate intraepithelial neoplasia but is rare in frank tumors [22]. Besides, elevated expression of the senescent marker $\beta$-galactosidase is associated with lower cancer stage and predicts reduced prostate specific antigen (PSA) recurrence within primary prostate tumor [23]. Although senescence in prostate epithelial cells is considered to be anti-tumorigenic, senescent stroma promotes cancer progression through the secretion of chemokines/cytokines and the remolding of extracellular matrix, providing a protumorigenic microenvironment.

Ginsenoside $\operatorname{Rg} 3$ has been reported to inhibit prostate cancer cell proliferation and migration, and enhance cancer cell sensitivity to chemotherapy. However, the effects of ginsenoside $\mathrm{Rg} 3$ on prostate stromal cells have not been clarified. Our research revealed the antisenescent effects of ginsenoside $\mathrm{Rg} 3$ through a decrease in SA- $\beta$-gal positive staining in prostatic stromal cells, both by incubation in low serum medium and by over-replication. Under serum starvation conditions, ginsenoside $\mathrm{Rg} 3$ promoted cell cycle transition to $\mathrm{S}$ phase from $\mathrm{G} 0 / \mathrm{G} 1$ during which senescent cells were arrested [24], down-regulated p21 expression (Supplementary
Figure 1), increased cell viability and proliferation, and inhibited stromal cell-induced cancer cell migration. In a replicative senescent model of primary cultured rat prostatic stromal cells, ginsenoside $\mathrm{Rg} 3$ decreased p21 expression and DNA damage, as indicated by the positive staining of $\gamma \mathrm{H} 2 \mathrm{~A}$.X that was observed in the replicative senescent stromal cells but not in cells treated with ginsenoside Rg3. Furthermore, no $\gamma \mathrm{H} 2 \mathrm{~A}$.X staining was observed in stromal cells incubated in serum starvation conditions.

SM22 is a $22 \mathrm{KD}$ actin-binding protein mainly expressed in smooth muscle cells and is considered a marker of smooth muscle differentiation. SM22 can act as a cancer repressor by modulating the secretion of matrix metalloproteinase 9 (MMP9) or the AR signaling pathway $[25,26]$. Another smooth muscle marker, SMMHC, is also reported to be down-regulated either in BPH or smooth muscle adjacent to prostate cancer sites [27, 28]. These results provide some clues about the phenotype of procarcinogenic stromal cells in the prostate. Our recent report also demonstrated the down-regulation of SM22 and SMMHC in carcinoma associated stromal cells [29]. Although the exact differentiation phenotype of senescent prostate stromal cells has not been fully identified, this research revealed an up-regulation of SM22 and SMMHC in ginsenoside $\mathrm{Rg} 3$-treated cells, indicating the compound may inhibit the pro-carcinogenic stromal phenotype.

Inflammatory factors, such as IL-6 and IL-8, contribute to cellular growth arrest and senescence [30, 31]. Our research evaluated the expression of several factors in ginsenoside Rg3-treated WPMY-1 cells and only down-regulation of IL- 8 was observed (Supplementary Figure 7). The role of IL-8 in cellular senescence is controversial. Medina et al. [32] pointed out that IL-8 is a facilitator of the outgrowth of endothelial cell senescence, while Shen et al. [15] highlighted the preventive role of IL-8 on oxidative stress-induced endothelial cell senescence. In our study, over-expression or exogenous addition of IL-8 completely reversed the inhibitory effects of ginsenoside $\operatorname{Rg} 3$ on the senescence of stromal cells incubated in low serum medium and on cancer cell migration induced by CM collected from stromal cells. These results identified IL- 8 as the pivotal modulator in ginsenoside Rg3-prevented stromal cell senescence.

IL- 8 has been reported as a potential therapeutic target in prostate cancer treatment [33], while the regulatory model of IL-8 expression in prostate stroma has not been fully elucidated. Previous report has suggested that ROS and the NF- $\mathrm{B}$ pathway are involved in IL-8 regulation [34]. In this research, ginsenoside Rg3 decreased ROS in stromal cells incubated in serum starvation conditions, while either $\mathrm{H}_{2} \mathrm{O}_{2}$ or $\mathrm{CoCl}_{2}$ up-regulated ROS levels and blocked the inhibitory effects of ginsenoside Rg3 on both ROS level and IL-8 expression. It was interesting that the ROS scavenger NAC, but not ginsenoside $\mathrm{Rg} 3$, was able to attenuate 
$\mathrm{CoCl}_{2}$-induced ROS increase and IL-8 expression. First, the results suggested that ROS has a regulatory role in IL-8 expression, as depletion of ROS by NAC downregulated IL-8 expression. Second, ginsenoside Rg3 and $\mathrm{H}_{2} \mathrm{O}_{2} / \mathrm{CoCl}_{2}$ may have different regulatory mechanisms in ROS modulation. Cellular ROS is mainly generated by mitochondria and NADPH oxidases (NOXs). We found that $\mathrm{Rg} 3$ down-regulated the mRNA expression of NOX4 (Supplementary Figure 7), which is one producer of ROS in cells [35], while a recent research indicated that depleting of mitochondrial DNA in liver tumor cells impaired $\mathrm{CoCl}_{2}$ induced ROS generation, which suggested mitochondria with intact function were essential in $\mathrm{CoCl}_{2}$ induced ROS up-regulation [36]. However, the exact role of NOX4 in the ginsenoside Rg3 regulation of IL-8 expression and in cellular senescence needs further exploration. Our research also analyzed transcriptional activity of the IL-8 gene promoter and revealed ginsenoside $\mathrm{Rg} 3$ decreased the recruitment of $\mathrm{C} /$ EBP $\beta$ and $p 65$ to their corresponding binding sites on the IL-8 promoter.

In conclusion, our study demonstrated that ginsenoside $\operatorname{Rg} 3$ prevented the senescence in prostate stromal cells, and inhibited cancer cell migration through a stromal-epithelial interaction. Ginsenoside Rg3 also decreased the IL-8 expression essential for inhibiting serum-starved stromal cell senescence. Decreased cellular ROS and attenuation of the binding of transcription factors C/EBP $\beta$ and $p 65$ to IL- 8 promoter mediated the inhibitory effects of ginsenoside Rg3 on IL-8 expression. Recent reports indicate that chemotherapy may induce stromal cell senescence, contributing to the chemoresistance of cancer cells [37] and this may be a possible reason for clinical chemotherapy failure. The research results lead to the novel suggestion of targeting the senescent stromal microenvironment, and assist in objective assessment of the use of ginsenoside $\mathrm{Rg} 3$ in prostate cancer treatment.

\section{MATERIALS AND METHODS}

\section{Cell culture and treatment}

Normal prostate stromal cell line WPMY-1 (American Type Culture Collection, USA) was cultured in DMEM medium (Sigma, USA), supplemented with 5\% FBS (Invitrogen, USA) and 1\% penicillin/streptomycin (P/S, Hyclone, USA). NAF (Normal-associated fibroblast) and CAF (carcinoma-associated fibroblast) cells, supplied by the Department of Urology of Medical University of Innsbruck (Innsbruck, Austria), were cultured in DMEM medium supplemented with $10 \%$ FBS and $1 \% \mathrm{P} / \mathrm{S}$. Prostate cancer cells PC3, supplied from the German Cancer Research Center (DKFZ) (Germany), were cultured in RPMI 1640 medium (Sigma, USA) supplemented with 1\% P/S and 10\% FBS. WPMY1 , NAF, and CAF cells were pre-incubated in DMEM medium supplemented with $0.5 \%$ FBS for $36 \mathrm{~h}$ followed by treatment with either vehicle (DMSO) or $25 \mu \mathrm{M}$ ginsenoside Rg3 (YiFang S\&T, China).

\section{SA- $\beta$-gal staining}

WPMY-1, NAF, and CAF cells were seeded into 6-well plates and treated with vehicle or ginsenoside Rg3 for $48 \mathrm{~h}$. A commercial SA- $\beta$-gal staining kit (Beyotime Institute of Biotechnology, China) was used according to the manufacturer's instructions. Senescent cells were identified as blue-stained by standard light microscopy (Leica, Germany), and photographs were taken using a phase-contrast microscope. Six view fields were randomly selected and the percentage of positive stained cells was calculated. The results were expressed as mean \pm standard deviation (SD).

\section{Cell viability assays}

WPMY-1 and NAF cells were treated with either vehicle or $25 \mu \mathrm{M}$ ginsenoside $\operatorname{Rg} 3$ for 0,24 , and $48 \mathrm{~h}$, respectively. 3-(4, 5-Dimethylthiazol-2-yl)-2, 5-diphenyltetrazolium bromide (MTT) (Sigma, USA) was added into the medium. Cell medium was discarded $2 \mathrm{~h}$ later and $250 \mu \mathrm{L}$ DMSO was added into each well. The absorbance at $570 \mathrm{~nm}$ was measured with a microplate reader (BioTek, USA). The results were expressed as mean of triplicates \pm SD.

\section{Cell cycle analysis}

WPMY-1 and CAF cells were treated with vehicle or ginsenoside $\mathrm{Rg} 3$ for $24 \mathrm{~h}$. Flow cytometry assays were used to analyze the cell cycle as previously reported [38].

\section{Immunofluorescence assays}

WPMY-1 and NAF cells were cultured onto the slides and treated with vehicle or ginsenoside Rg3 for 72 h. The slides were then fixed with $4 \%$ paraformaldehyde, washed with phosphate buffered saline (PBS) and treated with PBS containing 10\% FBS to block nonspecific reactions. The slides were incubated with primary antibodies (rabbit anti-SM22 [sc-50446, Santa Cruz, USA] and mouse anti-SMMHC [sc-6956, Santa Cruz, USA]) overnight at $2-8{ }^{\circ} \mathrm{C}$. Secondary antibodies (Alexa Fluor 488 donkey anti-rabbit IgG $[\mathrm{H}+\mathrm{G}]$ and Alex Fluor 594 goat anti-mouse $\operatorname{IgG}[\mathrm{H}+\mathrm{L}]$ [Life Technologies, USA]) labeled with green/red fluorescence were used for $1 \mathrm{~h}$ at $37^{\circ} \mathrm{C}$. The cell nucleus was labeled with 4, 6-diamino-2phenyl indole (DAPI) (Sigma, USA). Images were taken 
Table 1: Nucleotide sequence of primers used in this research

\begin{tabular}{|c|c|c|}
\hline Primer name & Sequence $(5,-3)$, & Purpose \\
\hline Human IL8 Sa & CTCTGGCAGCCTTCCTGATT & Real-time PCR \\
\hline Human IL8 ASb & TATGCACTGACATCTAAGTTCTTTAGC & Real-time PCR \\
\hline Human HPRT S & TGACACTGGCAAAACAATGCA & Real-time PCR \\
\hline Human HPRT AS & GGTCCTTTTCACCAGCAAGCT & Real-time PCR \\
\hline IL8 clone $\mathrm{S}$ & ATAGGATCCCCGGAAGGAACCATCTCA & PCDNA3.1-IL8 \\
\hline IL8 clone AS & AATCTCGAGCTGGCATCTTCACTGATTCTTG & PCDNA3.1-IL8 \\
\hline IL8 promoter-1481 & CGAGGTACCGAATTCAGTAACCCAGGCATTATT & IL-8 pro L \\
\hline IL8 promoter-765 & CGAGGTACCGCTCTTATGCCTCCACTG & IL-8 pro $\mathrm{M}$ \\
\hline IL8 promoter-176 & CGAGGTACCAAAACTTTCGTCATACTCCG & IL-8 pro $S$ \\
\hline IL8 promoter +44 & ATAAGATCTAGCTTGTGTGCTCTGCTGTCTCTGAAA & IL-8 pro L, M, S \\
\hline IL8 AP1 S & TGTGATATCTCAGGTTTGCCCTG & AP-1 mut \\
\hline IL8 AP1 AS & CAAACCTGAGATATCACACTTCCT & AP-1 mut \\
\hline IL8 C/EBP S & GCCATAGCTTGCAAATCGTGGAAT & C/EBP mut \\
\hline IL8 C/EBP AS & TTTGCAAGCTATGGCCCATCCC & $\mathrm{C} / \mathrm{EBP}$ mut \\
\hline IL8 NFאB S & ATCGTTAACTTTCCTCTGACATA & NF- $\kappa$ B mut \\
\hline IL8 NFKB AS & AAAGTTAACGATTTGCAACTGATG & NF- $\kappa \mathrm{B}$ mut \\
\hline ChIP S & ACTTTCGTCATACTCCG & ChIP assay \\
\hline ChIP AS & CACCCTCATCTTTTCAT & ChIP assay \\
\hline
\end{tabular}

a, Sense; b, Antisense.

using a fluorescent microscope (Leica, Germany) at $400 \times$ magnification.

\section{Western blot}

WPMY-1 and NAF cells were treated with vehicle or ginsenoside Rg3 for $72 \mathrm{~h}$. Proteins of cell extracts were resolved by sodium dodecyl sulfate polyacrylamide gel electrophoresis and transferred onto polyvinylidene difluoride (PVDF) membranes. The membranes were incubated with antibodies against SM22, SMMHC, and GAPDH (KC-5G4, Kangchen, China) overnight at 2 $-8{ }^{\circ} \mathrm{C}$. Proteins were detected by appropriate secondary antibodies (goat anti-rabbit or goat anti-mouse) conjugated with horseradish peroxidase (Bio-Rad, USA) followed by enhanced chemiluminescence detection (Amersham, USA). The results were quantified with Image J software and expressed as mean of triplicates \pm SD.

\section{Wound-healing assays}

WPMY-1 cells were treated with vehicle or ginsenoside Rg3 for 48 h. CMs were collected, centrifuged at $400 \mathrm{~g}$ for $5 \mathrm{~min}$ to remove the floating cells and normalized according to cell number and named CMCTRL and CM-Rg3 respectively. Unconditioned mediums (unCMs) DMEM-CTRL and DMEM-Rg3 (incubated DMEM medium supplied with vehicle or $25 \mu \mathrm{M}$ Rg3 in a cell incubator for $48 \mathrm{~h}$ ) were used as control. PC3 cells were cultured with RPMI1640 medium containing $0.5 \%$ FBS for 24 h. Each well was scratched with disposable tips in the cell monolayer. Each CM or unCM was mixed with RPMI1640 supplemented with $0.5 \%$ FBS in a $1: 2$ ratio. PC3 cells were treated with each mixture for $24 \mathrm{~h}$. Images were taken at $200 \times$ magnification under a phasecontrast microscope (Leica, Germany). Image J software was used to analyze the relative migration distance. The results were expressed as mean of triplicates $\pm \mathrm{SD}$.

\section{Transwell assays}

A protocol for transwell assays was followed according to our previous report [29]. Results were obtained from 3 independent experiments and quantitative results expressed as mean $\pm \mathrm{SD}$.

\section{RNA isolation and real time PCR}

Total RNA was extracted using Trizol reagent (Invitrogen, USA). Reverse transcription was performed with a commercial reverse transcription kit (Promega, USA). Real-time polymerase chain reaction (PCR) was performed using the specific primers listed in Table 1. The relative gene expression was determined using the comparative CT method and normalized to housekeeping gene hypoxanthine phosphoribosyltransferase 1 (HPRT).

\section{Human IL-8 ELISA assays}

CM was collected from WPMY-1 or NAF cells and centrifuged at $400 \mathrm{~g}$ for $5 \mathrm{~min}$ to remove the floating 
cells. CM volumes were normalized to cell numbers. The concentration of IL- 8 in CM was determined with ELISA kits (Boster, China) following the protocol of the manufacturer.

\section{Plasmids and transfection}

Human IL-8 cDNA fragment containing complete coding DNA sequence (CDS) region was obtained from the total RNA of WPMY-1 cells by reverse transcription and PCR amplification. The cDNA fragment was cloned into vector PCDNA3.1 (+) with the restriction enzymes BamH I and Xho I (Takara, Japan) and the over-expression plasmid was named PCDNA3.1-IL8. Human IL-8 gene promoter fragment $(-1481 \mathrm{nt}$ to $+44 \mathrm{nt})$ was amplified from genomic DNA isolated from WPMY-1. The fragment was cloned into PGL3-Basic plasmid with Kpn I and Bgl II (Takara, Japan) to construct the luciferase reporter plasmid IL-8 pro L ( $-1481 \mathrm{nt}$ to $+44 \mathrm{nt})$. Another two sense primers were used to construct the other two luciferase reporter plasmids: IL- 8 pro $\mathrm{M}(-765 \mathrm{nt}$ to $+44 \mathrm{nt})$ and IL- 8 pro $\mathrm{S}$ $(-176 \mathrm{nt}$ to $+44 \mathrm{nt})$. The primers are listed in Table 1 . The plasmid $\mathrm{pNF}-\kappa \mathrm{B}-\mathrm{luc}$ was a luciferase reporter with $4 \mathrm{NF}$ $\kappa \mathrm{B}$ motifs (Clontech, USA). Transfections were performed using Lipofectamine ${ }^{\mathrm{TM}} 2000$ (Invitrogen, USA). Luciferase assays were performed as described previously [39].

\section{Exogenous IL-8 addition}

WPMY-1/NAF cells were treated with vehicle, $25 \mu \mathrm{M}$ ginsenoside $\mathrm{Rg} 3,10 \mathrm{ng} / \mathrm{mL}$ human IL-8 protein (GenScript, USA), and human IL-8 protein $+\mathrm{Rg} 3$. After $48 \mathrm{~h}$, the cells were analyzed with SA- $\beta$-gal staining and the percentage of positive stained cells was calculated. The results were expressed as mean $\pm \mathrm{SD}$.

\section{ROS level assays}

WPMY-1 cells were treated with DMSO, $25 \mu \mathrm{M}$ $\mathrm{Rg} 3,600 \mathrm{mM} \mathrm{H}_{2} \mathrm{O}_{2}$ (Solarbio, China) and $\mathrm{Rg} 3+\mathrm{H}_{2} \mathrm{O}_{2}$, respectively. After $24 \mathrm{~h}$, an ROS assay kit (Beyotime institute of biotechnology, China) was used to evaluate ROS levels according to the protocol. The photographs were taken under a fluorescent microscope (Leica, Germany) at $200 \times$ magnification.

\section{In vitro mutagenesis of the $\mathrm{AP}-1, \mathrm{C} / \mathrm{EBP} \beta$, and $\mathrm{NF}-\kappa \mathrm{B}$ binding sites}

The AP-1, C/EBP $\beta$, and NF- $\kappa$ B binding sites on IL- 8 promoter were mutated by PCR respectively. The luciferase reporter plasmid IL-8 pro S was used as the template and the primers are listed in Table 1 . The PCR products were digested by Dpn I (Takara, Japan) for $3 \mathrm{~h}$ and transferred into DH5 $\alpha$ bacteria to obtain 3 corresponding mutated reporter plasmids, named as AP-1

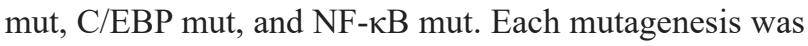
confirmed by DNA sequencing.

\section{ChIP assays}

WPMY-1 cells were treated with vehicle or ginsenoside Rg3 for another $24 \mathrm{~h}$. ChIP assays were then performed as described previously [39]. C/EBP $\beta$ (sc-150, Santa Cruz, USA) and p65 antibodies (ab7970, Abcam, UK) and control rabbit Igg (bs-0296P, Bioss, China) were used. The primers used in the ChIP assays are shown in Table 1 and the PCR product was $128 \mathrm{bp}$.

\section{Statistical analysis}

The results are expressed as mean $\pm \mathrm{SD}$. Significance was assessed using Student's paired t-test. $P<0.05$ was considered significant and $p<0.01$ highly significant.

\section{ACKNOWLEDGMENTS}

We cordially thank Dr. Shiwu Zhang of Tianjin People's Hospital for his valuable advice. We thank LetPub (www.letpub.com) for its linguistic assistance during the preparation of this manuscript.

\section{CONFLICTS OF INTEREST}

The authors declare that they have no competing interests.

\section{GRANT SUPPORT}

The research was supported by the Scientific Research Foundation of the School of Integrative Medicine at Tianjin University of Traditional Chinese Medicine, the National Natural Science Foundation of China (No. 81370859 and No. 81672527), the Natural Science Foundation in Tianjin (No. 16JCQNJC10700) and the Program for Changjiang Scholars and Innovative Research Team in University (No. IRT_14R41).

\section{REFERENCES}

1. Lackner DH, Hayashi MT, Cesare AJ, Karlseder J. A genomics approach identifies senescence-specific gene expression regulation. Aging cell. 2014; 13:946-950.

2. Elkhattouti A, Hassan M, Gomez CR. Stromal Fibroblast in Age-Related Cancer: Role in Tumorigenesis and Potential as Novel Therapeutic Target. Frontiers in oncology. 2015; $5: 158$. 
3. Begley L, Monteleon C, Shah RB, Macdonald JW, Macoska JA. CXCL12 overexpression and secretion by aging fibroblasts enhance human prostate epithelial proliferation in vitro. Aging cell. 2005; 4:291-298.

4. Bavik C, Coleman I, Dean JP, Knudsen B, Plymate S, Nelson PS. The gene expression program of prostate fibroblast senescence modulates neoplastic epithelial cell proliferation through paracrine mechanisms. Cancer research. 2006; 66:794-802.

5. Taddei ML, Cavallini L, Comito G, Giannoni E, Folini M, Marini A, Gandellini P, Morandi A, Pintus G, Raspollini MR, Zaffaroni N, Chiarugi P. Senescent stroma promotes prostate cancer progression: the role of miR-210. Mol Oncol. 2014; 8:1729-1746.

6. Lafkas D, Trimis G, Papavassiliou AG, Kiaris H. P53 mutations in stromal fibroblasts sensitize tumors against chemotherapy. International journal of cancer. 2008; 123:967-971.

7. Shan X, Fu YS, Aziz F, Wang XQ, Yan Q, Liu JW. Ginsenoside Rg3 inhibits melanoma cell proliferation through down-regulation of histone deacetylase 3 (HDAC3) and increase of p53 acetylation. PloS one. 2014; 9:e115401.

8. Tian L, Shen D, Li X, Shan X, Wang X, Yan Q, Liu J. Ginsenoside Rg3 inhibits epithelial-mesenchymal transition (EMT) and invasion of lung cancer by down-regulating FUT4. Oncotarget. 2016;7:1619-32. doi: 10.18632/ oncotarget.6451.

9. Liu WK, Xu SX, Che CT. Anti-proliferative effect of ginseng saponins on human prostate cancer cell line. Life Sci. 2000; 67:1297-1306.

10. Pan XY, Guo H, Han J, Hao F, An Y, Xu Y, Xiaokaiti Y, Pan Y, Li XJ. Ginsenoside Rg3 attenuates cell migration via inhibition of aquaporin 1 expression in PC-3M prostate cancer cells. Eur J Pharmacol. 2012; 683:27-34.

11. Kim SM, Lee SY, Cho JS, Son SM, Choi SS, Yun YP, Yoo HS, Yoon DY, Oh KW, Han SB, Hong JT. Combination of ginsenoside $\mathrm{Rg} 3$ with docetaxel enhances the susceptibility of prostate cancer cells via inhibition of NF-kappaB. Eur J Pharmacol. 2010; 631:1-9.

12. Chiarugi P, Paoli P, Cirri P. Tumor microenvironment and metabolism in prostate cancer. Semin Oncol. 2014; 41:267280.

13. Krtolica A, Campisi J. Cancer and aging: a model for the cancer promoting effects of the aging stroma. Int J Biochem Cell Biol. 2002; 34:1401-1414.

14. Acosta JC, Gil J. A role for CXCR2 in senescence, but what about in cancer? Cancer research. 2009; 69:2167-2170.

15. Shen $\mathrm{XH}, \mathrm{Xu} \mathrm{SJ}$, Jin $\mathrm{CY}$, Ding $\mathrm{F}$, Zhou YC, Fu GS. Interleukin-8 prevents oxidative stress-induced human endothelial cell senescence via telomerase activation. Int Immunopharmacol. 2013; 16:261-267.

16. Yan Z, Wang J, Li J, Jiang N, Zhang R, Yang W, Yao W, $\mathrm{Wu} \mathrm{W}$. Oxidative stress and endocytosis are involved in upregulation of interleukin-8 expression in airway cells exposed to PM2.5. Environ Toxicol. 2015.

17. Yoon SJ, Park JY, Choi S, Lee JB, Jung H, Kim TD, Yoon SR, Choi I, Shim S, Park YJ. Ginsenoside Rg3 regulates S-nitrosylation of the NLRP3 inflammasome via suppression of iNOS. Biochem Biophys Res Commun. 2015; 463:1184-1189.

18. Le X, Shi Q, Wang B, Xiong Q, Qian C, Peng Z, Li XC, Tang H, Abbruzzese JL, Xie K. Molecular regulation of constitutive expression of interleukin- 8 in human pancreatic adenocarcinoma. J Interferon Cytokine Res. 2000; 20:935946.

19. Schosserer M, Grubeck-Loebenstein B, Grillari J. [Principles of biological aging]. Z Gerontol Geriatr. 2015; 48:285-294.

20. Dean JP, Nelson PS. Profiling influences of senescent and aged fibroblasts on prostate carcinogenesis. British journal of cancer. 2008; 98:245-249.

21. Sharma S, Shin JS, Grimshaw M, Clarke RA, Lee CS. The senescence pathway in prostatic carcinogenesis. Pathology. 2010; 42:507-511.

22. Campisi J. Senescent cells, tumor suppression, and organismal aging: good citizens, bad neighbors. Cell. 2005; 120:513-522.

23. Wagner J, Damaschke N, Yang B, Truong M, Guenther C, McCormick J, Huang W, Jarrard D. Overexpression of the novel senescence marker beta-galactosidase (GLB1) in prostate cancer predicts reduced PSA recurrence. PloS one. 2015; 10:e124366.

24. Sherwood SW, Rush D, Ellsworth JL, Schimke RT. Defining cellular senescence in IMR-90 cells: a flow cytometric analysis. Proceedings of the National Academy of Sciences of the United States of America. 1988; 85:90869090.

25. Li Q, Shi R, Wang Y, Niu X. TAGLN suppresses proliferation and invasion, and induces apoptosis of colorectal carcinoma cells. Tumour Biol. 2013; 34:505-513.

26. Yang Z, Chang YJ, Miyamoto H, Ni J, Niu Y, Chen Z, Chen YL, Yao JL, di Sant'Agnese PA, Chang C. Transgelin functions as a suppressor via inhibition of ARA54-enhanced androgen receptor transactivation and prostate cancer cell growth. Mol Endocrinol. 2007; 21:343-358.

27. Lin VK, Wang D, Lee IL, Vasquez D, Fagelson JE, McConnell JD. Myosin heavy chain gene expression in normal and hyperplastic human prostate tissue. Prostate. 2000; 44:193-203.

28. Wong YC, Tam NN. Dedifferentiation of stromal smooth muscle as a factor in prostate carcinogenesis. Differentiation. 2002; 70:633-645.

29. Jia B, Gao Y, Li M, Shi J, Peng Y, Du X, Klocker H, Sampson N, Shen Y, Liu M, Zhang J. GPR30 promotes prostate stromal cell activation via suppression of ERalpha expression and its downstream signaling pathway. Endocrinology. 2016; 157:3023-3035.

30. Kuilman T, Michaloglou C, Vredeveld LC, Douma S, van 
Doorn R, Desmet CJ, Aarden LA, Mooi WJ, Peeper DS. Oncogene-induced senescence relayed by an interleukindependent inflammatory network. Cell. 2008; 133:10191031.

31. Acosta JC, O'Loghlen A, Banito A, Raguz S, Gil J. Control of senescence by CXCR2 and its ligands. Cell Cycle. 2008; 7:2956-2959.

32. Medina RJ, O'Neill CL, O'Doherty TM, Chambers SE, Guduric-Fuchs J, Neisen J, Waugh DJ, Simpson DA, Stitt AW. Ex vivo expansion of human outgrowth endothelial cells leads to IL-8-mediated replicative senescence and impaired vasoreparative function. Stem Cells. 2013; 31:1657-1668.

33. Aalinkeel R, Nair B, Chen CK, Mahajan SD, Reynolds JL, Zhang H, Sun H, Sykes DE, Chadha KC, Turowski SG, Bothwell KD, Seshadri M, Chen C, et al. Nanotherapy Silencing the Interleukin-8 Gene Produces Regression of Prostate Cancer by Inhibition of Angiogenesis. Immunology. 2016; 148:387-406.

34. Kim MH, Kim A, Yu JH, Lim JW, Kim H. Glutamine deprivation induces interleukin-8 expression in ataxia telangiectasia fibroblasts. Inflamm Res. 2014; 63:347-356.

35. Sampson N, Koziel R, Zenzmaier C, Bubendorf L, Plas E,
Jansen-Durr P, Berger P. ROS signaling by NOX4 drives fibroblast-to-myofibroblast differentiation in the diseased prostatic stroma. Mol Endocrinol. 2011; 25:503-515.

36. Marin JJ, Lozano E, Perez MJ. Lack of mitochondrial DNA impairs chemical hypoxia-induced autophagy in liver tumor cells through ROS-AMPK-ULK1 signaling dysregulation independently of HIF-1alpha. Free radical biology \& medicine. 2016; 101:71-84.

37. Skolekova S, Matuskova M, Bohac M, Toro L, Durinikova E, Tyciakova S, Demkova L, Gursky J, Kucerova L. Cisplatin-induced mesenchymal stromal cells-mediated mechanism contributing to decreased antitumor effect in breast cancer cells. Cell Commun Signal. 2016; 14:4.

38. Wang C, Du X, Yang R, Liu J, Xu D, Shi J, Chen L, Shao R, Fan G, Gao X, Tian G, Zhu Y, Zhang J. The prevention and treatment effects of tanshinone IIA on oestrogen/ androgen-induced benign prostatic hyperplasia in rats. $\mathrm{J}$ Steroid Biochem Mol Biol. 2015; 145:28-37.

39. Peng Y, Shi J, Du X, Wang L, Klocker H, Mo L, Mo Z, Zhang J. Prostaglandin E2 induces stromal cell-derived factor-1 expression in prostate stromal cells by activating protein kinase A and transcription factor Sp1. Int J Biochem Cell Biol. 2013; 45:521-530. 